\title{
GIS Enabled Condition Based Asset Management of Gas Distribution Network: A Case Study of Shahdara, Lahore Pakistan
}

\author{
Zia Ul Islam1, Sajid Rashid Ahmad1, Khurram Chohan1, Ather Ashraf² \\ ${ }^{1}$ Institute of Geology, University of the Punjab, Lahore, Pakistan \\ ${ }^{2}$ Punjab University College of Information Technology (PUCIT), University of the Punjab, Lahore, Pakistan \\ Email: ziamayo@gmail.com, sajidpu@yahoo.com, khuuramchohan2001@gmail.com, atherashraf@gmail.com
}

Received 23 June 2015; accepted 3 August 2015; published 7 August 2015

Copyright (C 2015 by authors and Scientific Research Publishing Inc.

This work is licensed under the Creative Commons Attribution International License (CC BY). http://creativecommons.org/licenses/by/4.0/

(c) (i) Open Access

\begin{abstract}
World energy consumption increased by 56 percent, from 524 quadrillion Btu in 2010 to 820 quadrillion Btu in 2040. The increased demand in energy consumption is fulfilled by different renewable and non-renewable sources such as petroleum, natural gas, electricity, nuclear etc. Natural gas is one of the most important sources of energy. SNGPL has been managing a 94,263 km long gas pipelines network covering approximately the northern part of Pakistan. In this paper we have presented the use of condition based maintenance (CBM) management techniques with a geographical information system (GIS) for asset management of a gas distribution network of SNGPL. The continuous monitoring and updating of asset data reveal where the assets are located and which needs maintenance or which lies in critical condition. The system helps to save time and reduce visits to the sites and labour reduction.
\end{abstract}

\section{Keywords}

Asset Management, Distribution, Pipeline Network, GIS

\section{Introduction}

With rapid increase in population and economic growth, world energy consumption has increased by 56 percent, from 524 quadrillion Btu in 2010 to 820 quadrillion Btu in 2040 [1]. The population demands on energy consumption are satisfied by divergent renewable and non-renewable sources such as natural gas, solar, wind, biomass, petroleum, coal, electricity, nuclear and other sources [2]. Natural Gas is broadly used in commercial, domestic and industrial units, and vehicles [3]. With the increased demand for energy [4] [5], energy companies 
must manage assets efficiently.

Asset management is a systematic process of maintaining, upgrading, and operating physical assets cost-effectively [6]. Valuable and cost effective realization of assets require an orderly approach which enables an organization to maximize its stature and starts delivering its strategic objectives through managing assets over the whole life cycle [7]. In other words, a working mechanism is required to be implemented in such a way to provide utilities with management capabilities for a healthy asset life cycle in order to meet the desired level of reliability at the lowest possible cost of ownership [8].

Asset managers require rich and accurate datasets before they can hold their organizations accountable for smarter decisions [9]. However, geographic information system (GIS) managers require accurate geospatial data to decide whether to repair versus replace or maintain versus run-to-failure any specific asset or system in the network [10]. Mature asset management work allows investment plans to be addressed quickly in an effective and transparent way [11]. Asset management can offer more comprehensive purchasing decisions, operating schemes, and maintenance scheduling for improving the return on capital investment [12].

GIS is beginning to deliver on its potential to support enterprise management and this platform is intended to present a spatially correct and graphical representation of the network, linked to associated databases of assets, attributes and customers [13]. GIS has emerged as a very powerful technology [14] because it allows users to integrate their data and methods in ways that support traditional forms of geographical analysis, such as map overlay analysis [15]. GIS helps to maintain asset knowledge which enables better use of available capacity such as size, pressure and inlet quantity of gas at stations making it possible to use existing pipeline infrastructure before embarking on an expensive new build [16].

Natural gas is transported through transmission and distribution system [17]. Figure 1 shows gas distribution system, a typical gas distribution system consisting of assets such as supply main pipes, feeder main pipes, service pipes, valves, reducers and regulator devices to control and regulate gas flow, and furthermore, joints and fittings are required to join different pipes and meters to measure inlet and outlet of gas [18].

Sui Northern Gas Pipelines Limited (SNGPL) is a core distribution and transmission company in Pakistan with 4,585,371 consumers. The distribution activities covering 2650 main towns along with adjoining villages in Punjab \& Khyber PakhtoonKhaw are organized through 13 regional offices. Distribution system consists of 94,263 KM of pipeline [19].

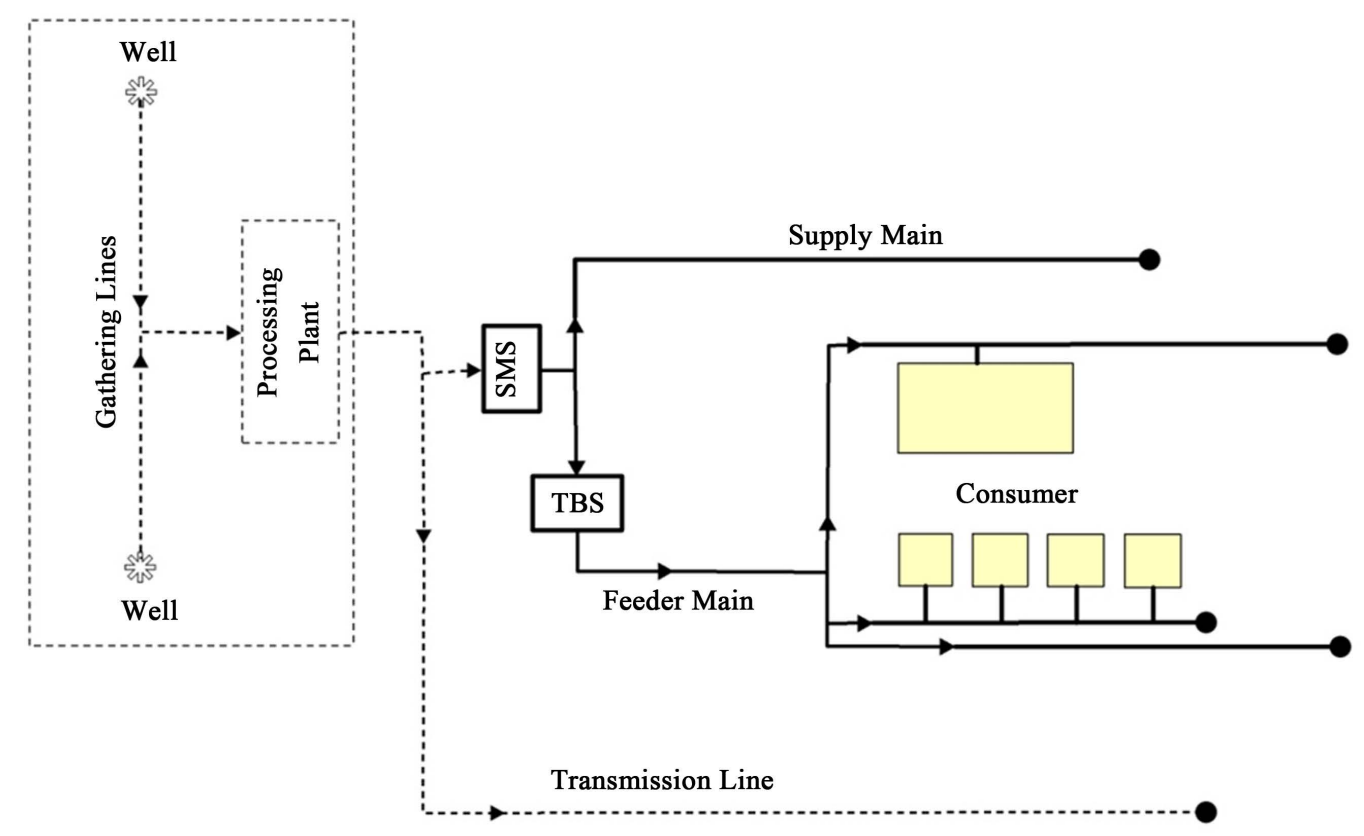

Solid Lines Part Represent the Typical Gas Distribution Network System 


\section{Asset Management Techniques}

Assets are better managed when their condition, maintenance and installation record is efficiently managed. Different management techniques such as maintenance strategies, determination of component condition, asset simulation and statistical fault analysis approach [20] can be followed. Figure 2 gives an overview of some different maintenance techniques. Condition based maintenance (CBM) uses primarily non-destructive testing techniques, visual inspection, maintenance history and performance data to assess asset condition [21] [22]. It requires improved instrumentation of the equipment and gradual checking of asset [23].

Most simple maintenance technique is corrective maintenance, only required when the asset breakdown occurs [24]. Usually, corrective maintenance is an unscheduled maintenance action, basically composed of unpredictable maintenance needs that cannot be preplanned [25]. Shorting the life time of asset and increased repairing labour cost are major drawbacks of corrective maintenance [26]. Time based maintenance action is performed on the asset at a scheduled time regardless of its actual condition [27]. Reliability Centered Maintenance (RCM) method employs preventive maintenance, predictive maintenace, real time monitoring, running to failure and proactive maintenance in an integrated way to provide more efficient solution for asset management [28]. However, it consumes large number resources which may increase cost with respect to time. SNGPL has been using condition based management system as an effective tool under economical resources.

\section{Data and Methods}

\subsection{Study Area}

Shahadra is a northern suburb (Town) of Lahore district, Pakistan. It is situated on the northern side of the Ravi River. The population of shahdara is 600,000 which are 4.8 percent of total population of city. Shahdara has many small industries including molding, steel, textile manufacturing and a thermal power plant. Mostly industry depends upon natural Gas. Figure 3 describe the study area boundary. The city extends from $74^{\circ} 14^{\prime} 12^{\prime \prime}$ to $74^{\circ} 18^{\prime} 44^{\prime \prime}$ of geographic longitude and from $31^{\circ} 38^{\prime} 37^{\prime \prime}$ to $31^{\circ} 36^{\prime} 19^{\prime \prime}$ of geographic latitude.

\subsection{Data Sources}

The working method is made up of three phases. In the first phase, requirement analysis is done, in which the needed spatial and attribute data are identified. The information is gathered and digitized with spatial information system. In the second phase the input data is analyzed and transform to their respective layers. Distribution pipeline network assets require the following data layers: i) Sales meter station layer; ii) Pipelines layer; iii) Town Border Station layer; iv) Valve layer; v) Reducer layer; vi) CP Station. In the last phase output of second phase examined and necessary suggestions are made.

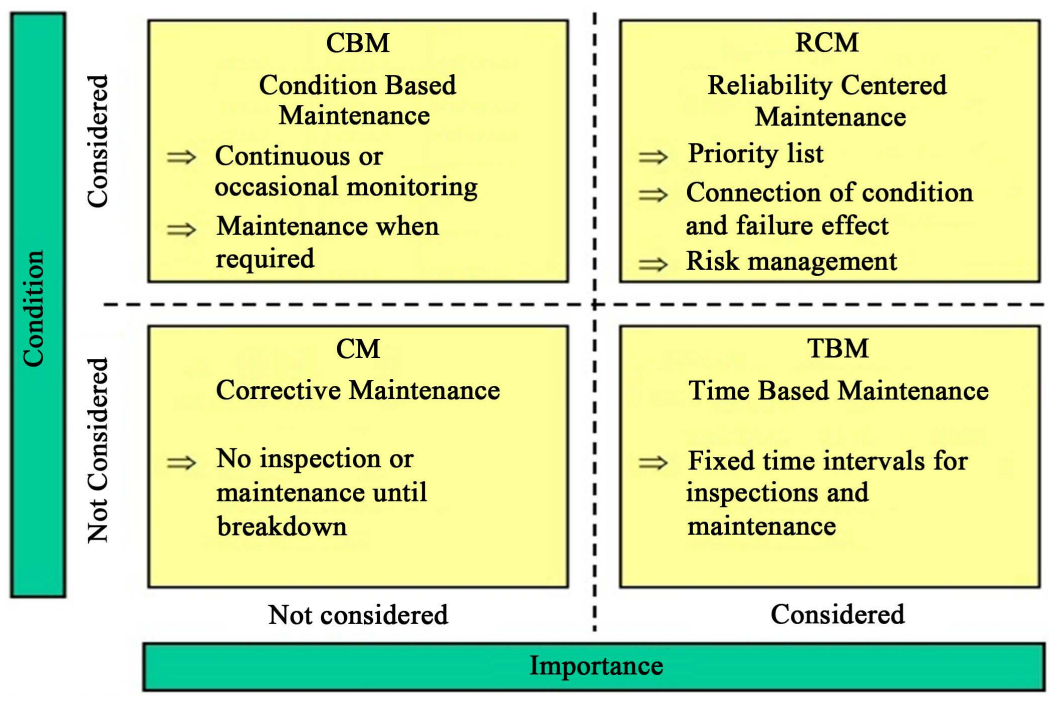

Figure 2. Maintenance management techniques (Schneider et al., 2005). 


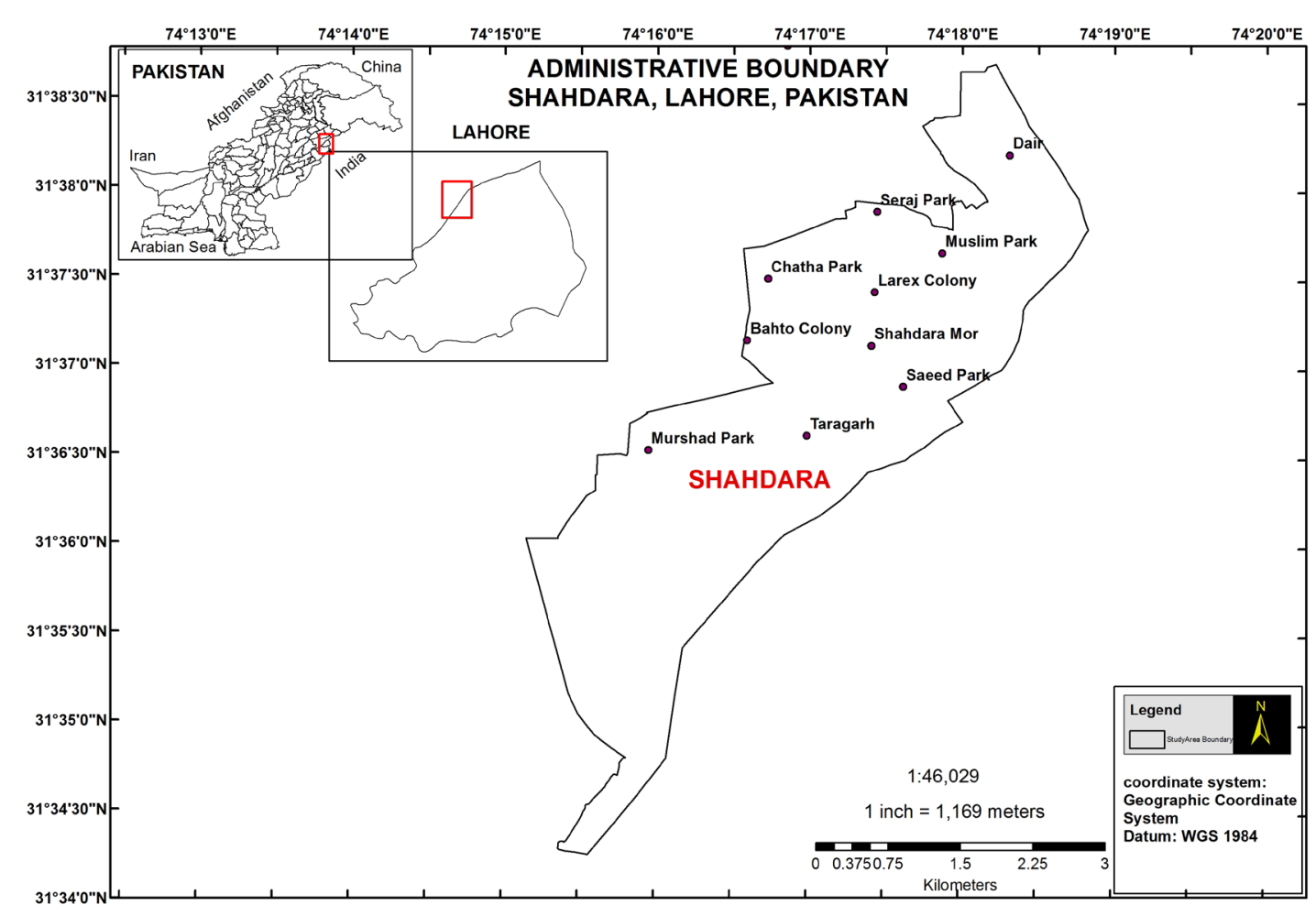

Figure 3. Study area.

The major data required for spatial database preparation are i) Distribution layout drawings; ii) Attribute data of related pipeline network. Distribution pipeline network is managed manually by handmade layout drawings. Those are collected from drawing section of Sui Northern Gas Pipelines Limited. These Drawings contains the pipeline network information that includes pipeline, Town Border Station, Sales Meter Station, CP Station, Reducer and valve information.

Layout Drawings are scanned and stored in jpg digital format. These drawings are geo referenced with projected coordinate system UTM zone 43 with datum WGS84. Following GIS layers are prepared by using GIS software: i) Sales meter station layer; ii) Pipelines layer; iii) Town Border Station layer; iv) Valve layer; v) Reducer layer; vi) CP Station using ArcGIS 9.3. Global positioning system survey is carried out for geographic location of gas distribution network features. Related attribute data of Pipeline network features are collected from distribution department. Attribute data is prepared in spread sheets and integrated with spatial data.

\subsection{Methodological Framework}

Main architecture of the methodology has been sketched in Figure 4 using Condition Based Maintenance Management approach. Conventional handmade maps and manually handled asset record books of the study area have been acquired from distribution department of SNGPL as a preliminary datasets. Manual maps have been geo-referenced on which Gas Pipelines, Town Boundary Stations (TBS), Valve locations, Pipeline Reducer locations, and Cathodic Protection (CP) sites are identified and stored in geo-database for further network and asset analysis. Besides, manual asset records like pipeline (diameter, length, Electric current in ampere, wall thickness), TBS (size, type, wild growth, fence, regulators, condition of floor, painting remarks), CP (AC to DC voltage converter and regulators condition), valve (size, painting, maintenance date, cracking lubrication) reducer (type, size, ) have been spatially joined with geodatabase.

GPS based surveys were conducted for ground validations of assets after which geo-database was promoted for correct and accurate analysis. Asset condition reports have been generated spatially to analyse asset condition and maintenance requirements using ground validated dataset of the study area. Finally, geodatabase has been deployed in SNGPL and therefore, it is intended to be updated approximately twice a week for accurate, up to date, and uninterrupted piece of information of assets condition to its employees. 


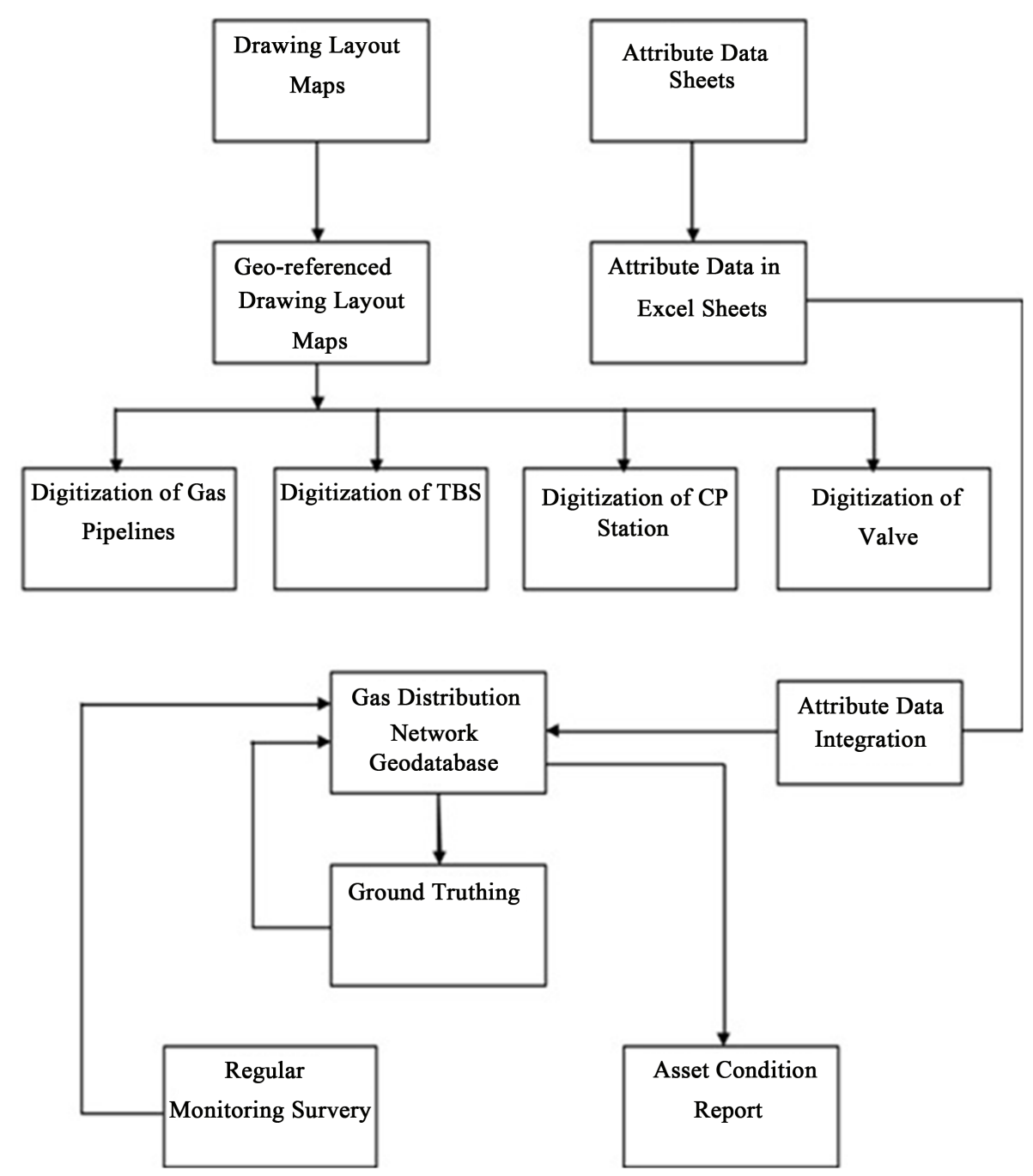

Figure 4. Methodological framework.

\section{Results and Discussions}

\subsection{Gas Pipeline Analysis}

Gas pipeline network summary describes the total number of pipeline network assets. Gas Pipeline analysis involve the summary of pipeline according to diameter, classification, Gas Pipeline type and total gas pipelines in the study area.

Table 1 shows the total number of related assets in gas distribution network and Table 2 represents the total length of gas pipelines and also categorizes the length of pipeline according to respective diameter.

It is observed from Table 2 that total length of pipelines in Shahdra is 420 kilometers. Results show that $7.1 \%$ of total gas pipeline is polyethylene (plastic) in Figure 5. For small diameter gas pipeline, polyethylene is widely used nowadays. Figure 6 represents the polyethylene and M.S pipelines.

\subsection{Town Border Station Analysis}

Town Border System reduces the gas pressure from supply main pipeline to distribution lines. It consists of regulator, valves, Pressure gauge, fence and RCC Slab. Proper painting and cleaning is required to prevent from erosion and environmental effects.

According to Table 3, Total Town Border Stations in Shahdara gas distribution network are 12. Table 3 describes the TBS condition and associated critical condition weight. Total 7 TBS are found that are missing pres- 


\section{Gas Pipline Length (Km)}
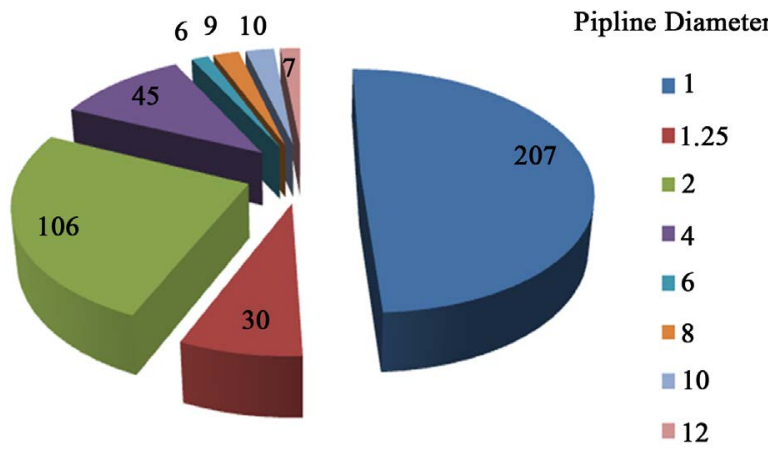

Figure 5. Gas pipeline length in kilometers with reference to pipeline diameter.

Table 1. Gas distribution network statistical summary.

\begin{tabular}{ccc}
\hline Sr. No. & Pipeline Network Feature & Counts \\
\hline $\mathbf{1}$ & Valve & 174 \\
$\mathbf{2}$ & TBS & 12 \\
$\mathbf{3}$ & CP Station & 3 \\
$\mathbf{4}$ & SMS & 1 \\
$\mathbf{5}$ & Pipeline & $420 \mathrm{KM}$ \\
\hline
\end{tabular}

Table 2. Gas pipeline summary.

\begin{tabular}{ccc}
\hline Pipeline Diameter & Length (KM) \\
\hline $\mathbf{1}$ & $\mathbf{1 . 2 5}$ & 201 \\
$\mathbf{2}$ & 30 \\
$\mathbf{4}$ & 106 \\
$\mathbf{6}$ & 45 \\
$\mathbf{8}$ & 6 \\
$\mathbf{1 0}$ & 9 \\
$\mathbf{1 2}$ & 10 \\
Total & $\mathbf{7}$ \\
& $\mathbf{4 2 0} \mathbf{K M}$ \\
\hline
\end{tabular}

Table 3. TBS condition summary.

\begin{tabular}{|c|c|c|c|c|c|}
\hline TBS Name & Fence & Painting & Wild Growth & Pressure Gauge & Critical Condition Weight \\
\hline TBS-1 Nain Sukh & 0 & 1 & 1 & 0 & 0.50 \\
\hline TBS-2 Main Shahdara & 1 & 1 & 1 & 1 & 0.00 \\
\hline TBS-3 Khurshid Park & 1 & 0 & 0 & 1 & 0.50 \\
\hline TBS-4 Faizpur & 0 & 0 & 1 & 1 & 0.50 \\
\hline TBS-5 Imamia Colony & 1 & 0 & 0 & 1 & 0.50 \\
\hline TBS-6 Rachna Town & 1 & 1 & 1 & 1 & 0.00 \\
\hline TBS-7 Shukat Town & 1 & 1 & 1 & 0 & 0.25 \\
\hline TBS- 8 Kot Abdul Malik & 1 & 1 & 0 & 0 & 0.50 \\
\hline TBS-9 Ismail Park & 0 & 1 & 1 & 0 & 0.50 \\
\hline TBS-10 Sui Gas Office & 0 & 0 & 0 & 1 & 0.75 \\
\hline TBS-11 Toll Plaza & 1 & 1 & 1 & 0 & 0.25 \\
\hline TBS-12 Suleman \& Company & 1 & 1 & 1 & 0 & 0.25 \\
\hline
\end{tabular}




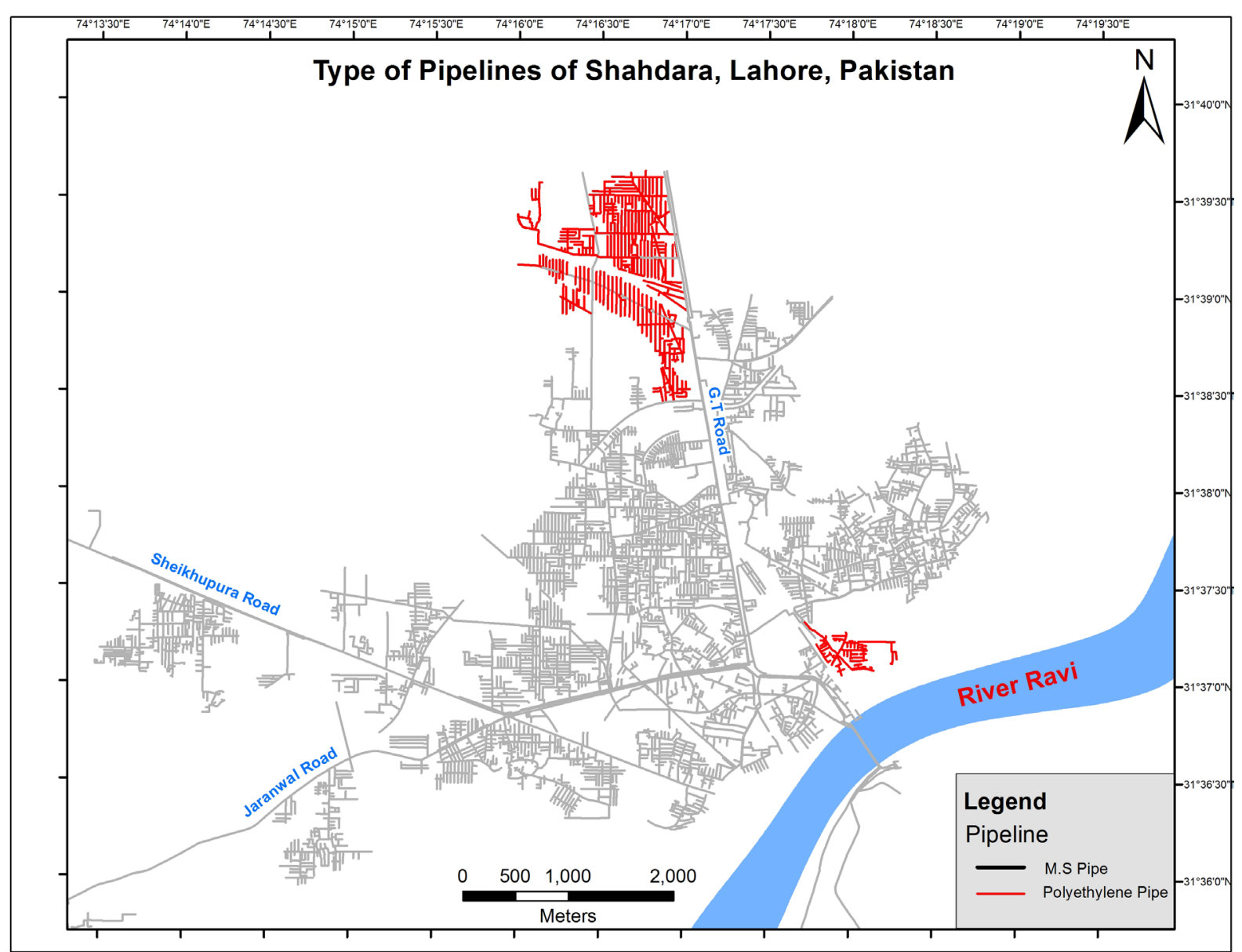

Figure 6. Polyethylene gas pipelines.

sure gauge, 5 TBS with poor painting and 4 TBS with no fence. It is also observed that 8 TBS need proper cleaning in order to remove wild growth.

Figure 7 describes the spatial distribution of TBS and it shows that TBS 10 has the most critical condition as with missing fence, wild growth and poor painting having critical weight 0.75 . Critical weight is calculated as

$$
C C W-1-\frac{\sum C v}{N}
$$

where, $C C W=$ Critical Condition Weight;

$C v=$ Condition value;

$N=$ Total condition.

\subsection{Valve Analysis}

Valve functions can be defined as ON/OFF service, throttling service (flow control), prevention of reverse flow (or back flow), pressure control, regulation and pressure relief. Effective valve maintenance can be accomplished using cleaners and introducing the proper lubricant at regular and frequent intervals.

According to Table 1 statistics, total valve in Shahdara pipeline gas distribution network are 174. It is observed from Table 4 that $21.26 \%$ valves are found in poor lubrication, $42.52 \%$ in poor painting, $4.02 \%$ with broken slab and $2.29 \%$ with missing pit cover out of 174 valves.

The graphical representation of valve condition factors with respective percentage is shown in Figure 8 . There are 3 valves which have been under critical condition in Shahdara's scenario with poor painting, poor lubrication as well as broken slab as shown in Figure 9. 


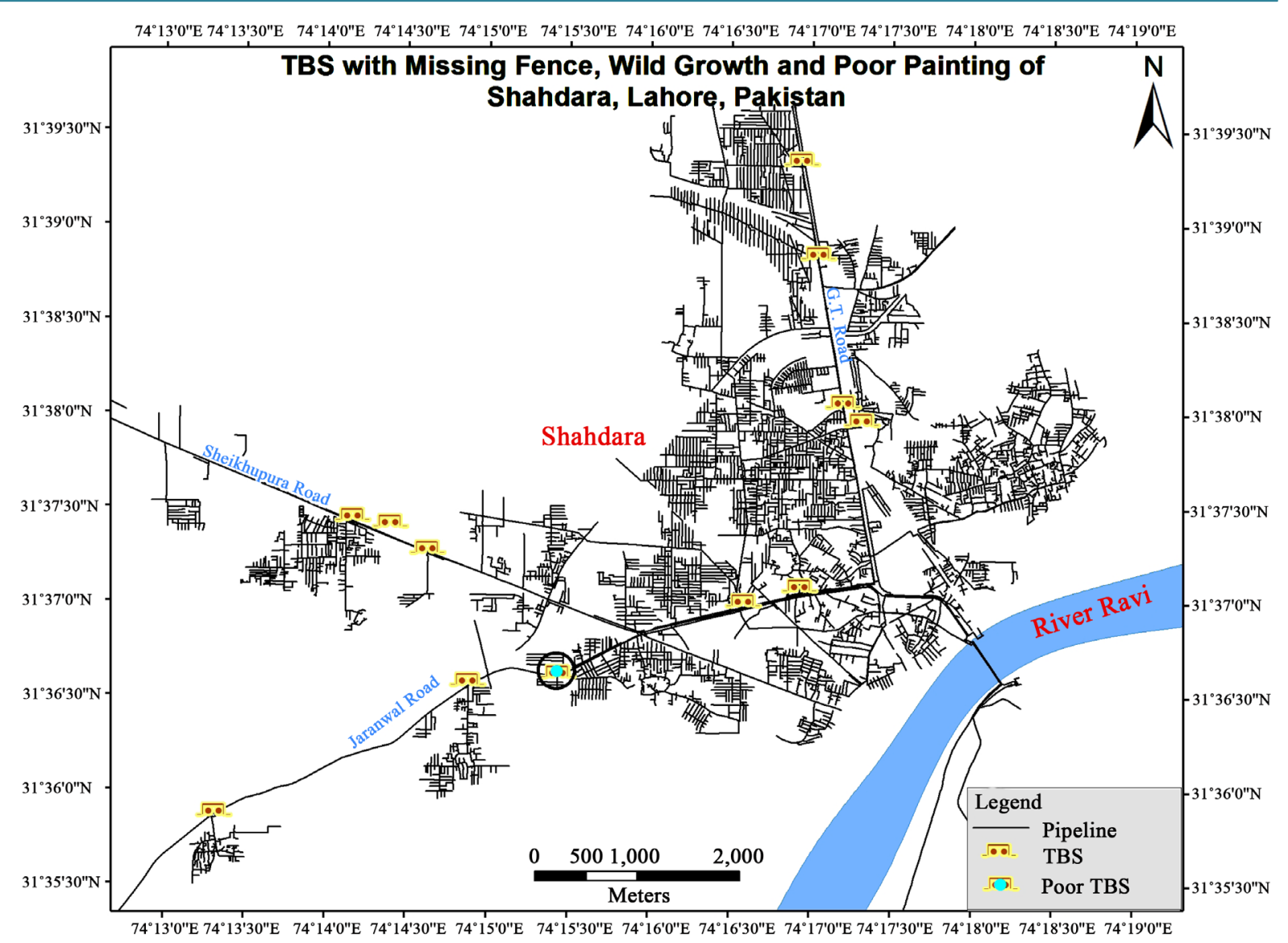

Figure 7. Poor TBS.
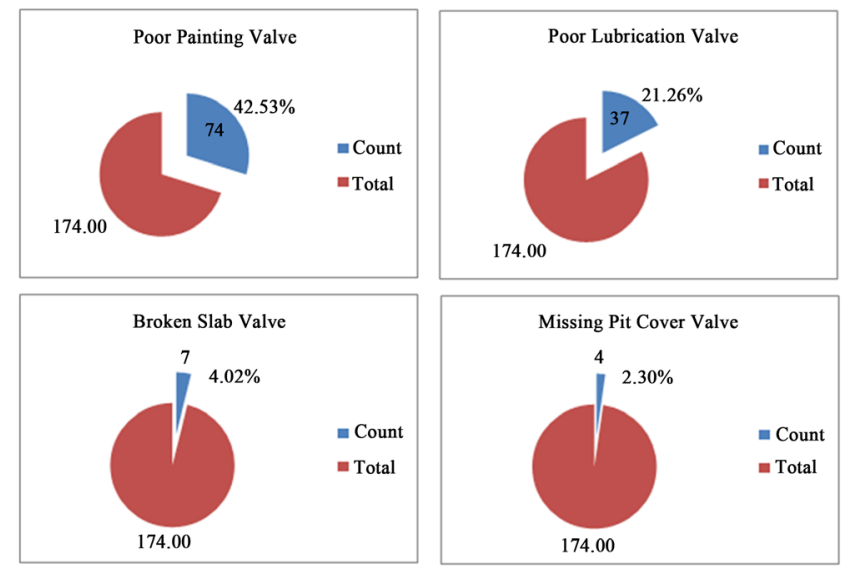

Figure 8. Graphical representations of valve condition and their respective percentage.

Table 4. Valve condition.

\begin{tabular}{cccc}
\hline Sr. No. & Analysis & Counts & Percentage (\%) \\
\hline $\mathbf{1}$ & Valve with poor lubrication & 37 & $21.26 \%$ \\
$\mathbf{2}$ & Valve with poor painting & 74 & $42.53 \%$ \\
$\mathbf{3}$ & Valve with broken RCC Slab & 7 & $4.02 \%$ \\
$\mathbf{4}$ & Valve with missing pit cover & 4 & $2.30 \%$ \\
\hline
\end{tabular}




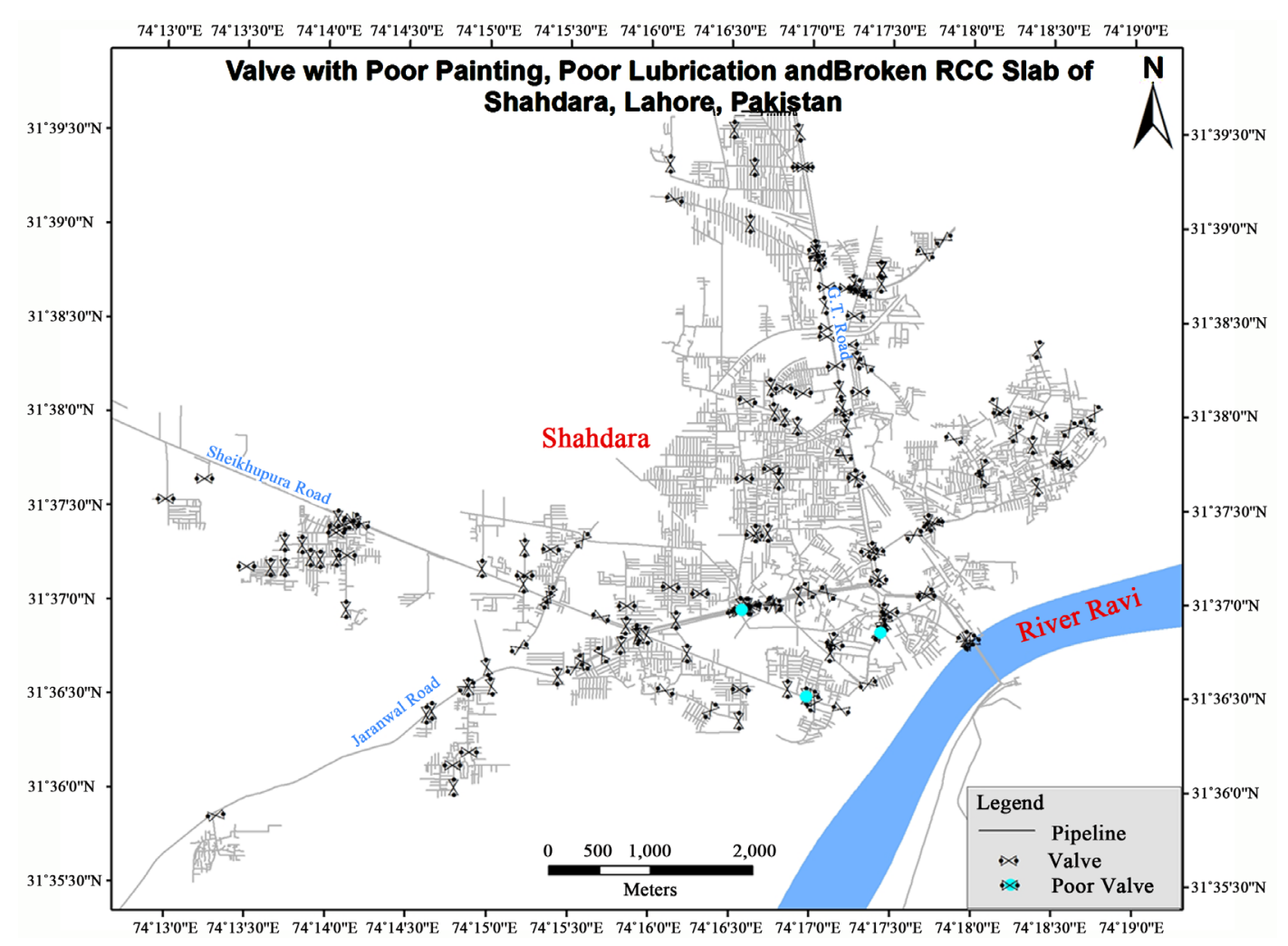

Figure 9. Poor valve.

\subsection{CP Station Analysis}

CP system is used to prevent buried iron and steel pipelines from corrosion. CP works by preventing the anodic reaction of metal dissolution occurring on the structure under protection. Sacrificial anode cathodic protection and impressed current cathodic protection techniques are used in field. SNGPL widely use impressed current cathodic protection technique.

Table 1 shows total 3 CP Station is found in shahdara pipeline network. Table 5 describes the CP Station condition summary. It is found that $1 \mathrm{CP}$ Station is suffered from wild growth which need proper cleaning and 2 CP Station needs proper painting. Figure 10 describes the CP-Station affected by wild growth and is installed on 6 inch supply main pipeline. Rests of 2 CP-Station with poor painting are installed on 4 inch and 12 inch pipelines.

\section{Conclusion}

The study applies the CBM model to gas distribution pipeline network asset management in SNGPL. Gas distribution pipeline network is spatial in nature. The integration of CBM model and GIS takes an advantage over manual and conventional system. The development of GIS system of gas distribution network provides the spatial distribution of pipeline network. It helps the spatial location of each network asset. Implementation of CBM model gives information about asset condition of pipeline network. The result shows that $7.1 \%$ of total gas pipeline is polyethylene which is not affected by any corrosion process. 1 TBS out of 12 is under severe condition which lacks of poor painting, missing fence, wild growth and missing pressure gauge. $42.53 \%$ of total valves bear poor painting and $1 \mathrm{CP}$ Station effect with wild growth. Asset management has been considered as a key component for managing records of assets. Therefore, the system is able to go on continuous monitoring, save time, and make effusive visits to the sites and labour reduction. Distribution of natural gas to the consumer through gas distribution network has become efficient and smarter than ever before. In addition to what has just been stated above, the system is made able to update and modify assets and appropriate locations for installing of new assets can also be investigated through GIS maps. The continuous monitoring and updating of asset data 


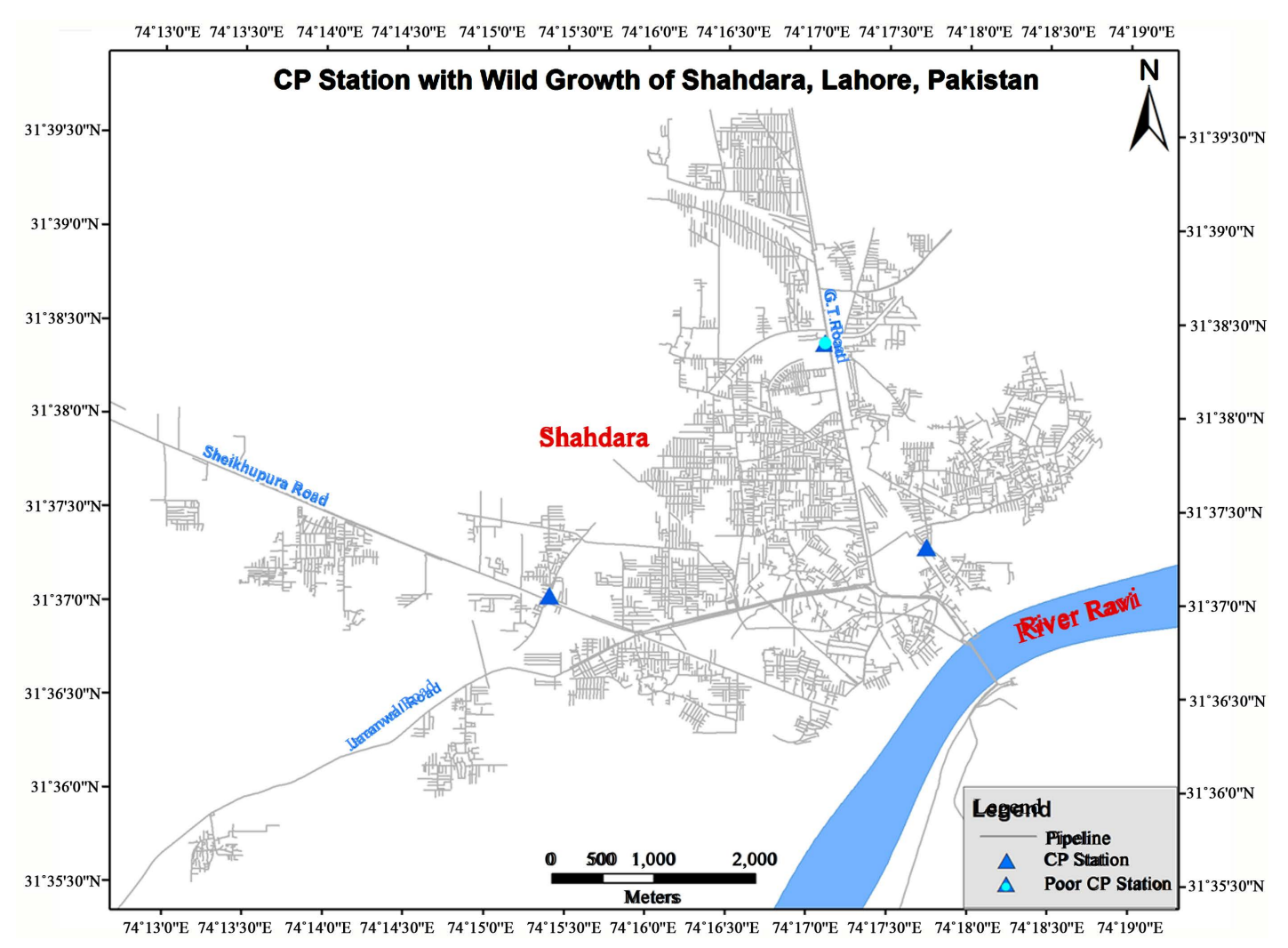

Figure 10. Poor CP station.

Table 5. CP station condition.

\begin{tabular}{ccc}
\hline Sr. No. & Analysis & Counts \\
\hline $\mathbf{1}$ & CP Station with wild growth & 01 \\
$\mathbf{2}$ & CP Station with poor painting & 02 \\
\hline
\end{tabular}

reveal where the assets are located and which needs maintenance or which lies in critical condition. The system can be improved by implementing RCM model for real time monitoring of assets, and different multiple monitoring factors however can be made on cost of implementation of RCM model.

\section{References}

[1] IEA (2013) World Energy Outlook 2013. IEA, Washington DC.

[2] Martinot, E., Chaurey, A., Lew, D., Moreira, J.R. and Wamukonya, N. (2002) Renewable Energy Markets in Developing Countries. Annual Review of Energy and the Environment, 21, 309-348. http://dx.doi.org/10.1146/annurev.energy.27.122001.083444

[3] MIT (2010) The Future of Natural Gas: An Interdisciplinary Mit Study. MIT, Cambridge.

[4] Garcia, O.G., Croiset, E., Douglas, P., Elkamel. A. and Gupta, M. (2007) Modeling the Energy Demands and Greenhouse Gas Emissions of the Canadian oil Sands Industry. Energy \& Fuels, 21, 2098-2111. http://dx.doi.org/10.1021/ef0700984

[5] Fouquet, R. (2013) Long Run Demand for Energy Services: the Role of Economic and Technological Development. Basque Centre for Climate Change [online]. http://www.bc3research.org/lits publications.html

[6] Center for Infrastructure and Transportation Studies (1997) 21st Century Asset Management. American Association of State Highway and Transportation Officials (AASHTO), New York.

[7] British Standard Institution (2008) PAS 55-1. Asset Management, Part 1: Specification for Optimized Management of 
Physical Assets.

[8] Mohseni, M. (2003) What Does Asset Management Mean to You? 2003 IEEE PES Transmission and Distribution Conference and Exposition, Dallas, 7-12 September 2003, 962-964.

[9] Natadarma, M.R. (2012) Enterprise Analytics Adoption Model: An Exploratory Study in Transforming an Organization towards Analytical Competitor. Master Thesis, Delft University of Technology, Delft.

[10] Butera, R. (2003) Integrating a Physical Strategy With a Data Strategy to Create Breakthrough Asset Management. 2003 Rural Electric Power Conference, Raleigh-Durham, 4-6 May 2003, B2-1-B2-8.

[11] Arup, S., Lahiri, R.N., Chowdary, S.P. and Song, Y.H. (2007) Complete IT Solution for Enterprise Asset Management (EAM) in Indian Power Utility Business. Proceedings of the 42nd International Universities Power Engineering Conference, Brighton, 4-6 September 2007, 645-650.

[12] Shahidehpour, M. and Ferrero, R. (2005) Time Management for Assets: Chronological Strategies for Power System Asset Management. IEEE Power and Energy Magazine, 3, 32-38. http://dx.doi.org/10.1109/MPAE.2005.1436498

[13] Fazal, S. (2008) GIS Basics. New Age International Limited Publishers, New Delhi.

[14] Mishra, S. (2009) GIS in Indian Retail Industry-A Strategic Tool. International Journal of Marketing Studies, 1, 50-57. http://dx.doi.org/10.5539/ijms.v1n1p50

[15] Smith, A.D. (2007) Achieving Competitive Advantage through the Use of Geographic Information Systems. Electronic Government: An International Journal (EG), 4, 326-344.

[16] Chutkay, S. (2009) Geospatial World. www.geospatialworld.net/:http://geospatialworld.net/Paper/Application/ArticleView.aspx?aid=1515

[17] Folga, S. (2007) Natural Gas Pipeline Technology Overview. US Department of Energy, Oak Ridge. http://dx.doi.org/10.2172/925391

[18] Australian Energy Regulator (2009) State of the Energy Market 2009. Australian Competition and Consumer Commission, Melbourne.

[19] SNGPL (2003) Sui Northern Gas Pipelines Limited. www.sngpl.com.pk:http://www.sngpl.com.pk/index2.jsp?pgids=322\&pgname=PAGES NAME\&secs=ss7xa8520p845 $\underline{\text { \&cats }=\text { ct } 456712337 \& \text { artcl }=\operatorname{artuyh} 709123465}$

[20] Schneider, J., Gaul, A. and Neumann, C. (2005) Asset Management Techniques. Proceedings of the 15th Power Systems Computation Conference, Liège, 22-26 August 2005, 1-11.

[21] Sethiya, S.K. (2006) IRSME. http://irsme.nic.in/files/cbm-sethiya.pdf

[22] Cheng H. (2007) Implementation Strategies and Tools for Condition Based Maintenance at Nuclear Power Plants. International Atomic Energy Agency, Vienna.

[23] IEA (2007) Implementation Strategies and Tools for Condition Based Maintenance at Nuclear Power Plants. IEA, Vienna.

[24] Hilber, P. (2005) Component Reliability Importance Indices for Maintenance Optimization of Electrical Networks. Ph.D. Thesis, Royal Institute of Technology, Stockholm.

[25] Dhillon, B.S. (2002) Engineering Maintenance: A Modern Approach. CRC Press LLC, Boca Raton. http://dx.doi.org/10.1201/9781420031843

[26] Sullivan, G.P., Pugh, R., Melendez, A.P. and Hunt, W.D. (2010) Operations \& Maintenance Best Practices: A Guide to Achieving Operational Efficiency. US Department of Energy, Washington DC. http://dx.doi.org/10.2172/1034595

[27] Etim, C., Ogaji, S.O.T. and Probert, S.D. (2006) Development and Implementation of Preventive-Maintenance Practices in Nigerian Industries. Applied Energy, 83, 1163-1179. http://dx.doi.org/10.1016/j.apenergy.2006.01.001

[28] Afefy, I.H. (2010) Reliability-Centered Maintenance Methodology and Application: A Case Study. Engineering, 2, 863-873. http://dx.doi.org/10.4236/eng.2010.211109 